[Article]

\title{
基于直接关系图方法的丁酸甲酯燃烧反应机理的框架简化
}

\author{
王全德" \\ (中国矿业大学低碳能源研究院, 江苏徐州 221008)
}

\begin{abstract}
摘要: 由于直接关系图(DRG)方法的概念简单和计算量较小, 使得 DRG 方法目前已经成为详细燃烧反应机 理框架简化的主流方法。DRG 方法中评价物种之间依赖关系的相互作用系数和关系图连接权重的计算方法 控制着DRG 方法的简化效果。采用四种不同形式的相互作用系数的定义方法, 分别与标准的DRG 搜索算法 和基于误差传播的搜索算法结合, 构建了丁酸甲酯的框架燃烧反应机理。通过系统的误差分析比较了不同简 化方法构建的框架机理的模拟可靠性。重点采用基于元素流量分析的反应路径分析方法研究了框架机理的化 学动力学。最后, 通过交集的思想构建了一个只包含 96 个物种的丁酸甲酯框架燃烧反应机理, 并且反应路 径分析结果表明丙烯的燃烧化学动力学在丁酸甲酯燃烧过程中占有重要地位。本文通过对不同 DRG 方法的 系统比较研究表明了反应路径分析在框架机理可靠性验证中的重要性, 对进一步发展更为有效的框架简化方 法提供重要依据。
\end{abstract}

关键词: 燃烧反应机理; 直接关系图方法; 框架简化; 丁酸甲酯

中图分类号: 0643

\section{Skeletal Mechanism Generation for Methyl Butanoate Combustion via Directed Relation Graph Based Methods}

\author{
WANG Quan-De* \\ (Low Carbon Energy Institute, China University of Mining and Technology, Xuzhou 221008, Jiangsu Province, P. R. China)
}

\begin{abstract}
Directed relation graph (DRG) based skeletal reduction methods have become the mainstream approach for skeletal mechanism generation because of their simple concept and low computational cost. Within the DRG framework, the definitions of the interaction coefficients and the connection weights in different DRG methods control the resulting skeletal mechanisms. In this work, based on DRG methods, four contemporary definitions of the interaction coefficients in conjunction with both standard DRG and error propagation (EP) graph search methods are used to derive skeletal mechanisms for methyl butanoate (MB) combustion. Detailed comparisons of contemporary DRG based methods are performed by systematic error analysis. To further evaluate the performance of the different DRG-based methods, reaction paths are investigated via element flux analysis to check the chemical kinetics of the resulting skeletal mechanisms. Furthermore, a 96-species skeletal mechanism for MB combustion is proposed. Reaction path analysis highlights the importance of propene chemistry during MB oxidation. This work reveals the applicability of reaction path analysis in skeletal reduction using different DRG-based methods, and also provides critical information for further development of skeletal reduction methods.
\end{abstract}

Key Words: Combustion mechanism; Directed relation graph method; Skeletal reduction; Methyl butanoate

Received: October 15, 2015; Revised: December 18, 2015; Published on Web: December 21, 2015.

*Corresponding author. Email: wqd198686@126.com.

The project was supported by the Fundamental Research Funds for the Central Universities of China (2013QNA08) and National Natural Science Foundation of China (21403296).

中央高校基本科研业务费专项资金(2013QNA08)和国家自然科学基金(21403296)资助项目

(C) Editorial office of Acta Physico-Chimica Sinica 


\section{Introduction}

In the past few years, the development of detailed combustion reaction mechanisms of practical fuels has grown by orders of magnitude, and the sizes of these mechanisms increase from 1020 species for hydrogen combustion to more than thousands of species in many recent detailed mechanisms for practical fuels ${ }^{1-4}$. It has been confirmed that detailed reaction mechanisms can provide more accurate predictions of the combustion properties of fuels, including ignition delay times, laminar flame speed, and the formation of pollutions over wide ranges of temperature, pressure and compositions $^{5-7}$. However, incorporating such detailed mechanisms into multidimensional combustion simulations remains a great challenge due to the huge demands of computational resources and the stiff problem induced by the different timescales of species and reactions in the detailed mechanisms. Therefore, in order to make numerical simulations of combustion computationally affordable and comprehensively reliable, the development of computational methods for rigorous reduction of detailed mechanisms is essential.

The development of mechanism reduction methods has made significant progress and a variety of methodologies have been developed ${ }^{8,9}$. Mechanism reduction methods are generally classified into two classes ${ }^{10}$ : the first is skeletal reduction, which directly removes unimportant species and reactions from the detailed mechanism; the other approach is timescale reduction which is via the decomposition of motion in phase space into fast and slow modes. Elimination of unimportant species and reactions from detailed mechanisms can reduce the computational cost significantly, since the computational cost of simulations typically scales quadratically with the number of species, while only linearly with the number of reactions. Therefore, skeletal reduction is typically the first step in mechanism reduction. The detection of unimportant species can be effectively achieved via careful inspection of the Jacobian matrix, and various methods including the computational singular perturbation (CSP) method ${ }^{10-12}$, level of importance (LOI) ${ }^{13}$, and connectivity method (CM) ${ }^{14,15}$ have been developed. Another class of approach for species elimination is based on graph theory, which was initially introduced by Bendtsen et al. ${ }^{16}$. In 2005, Lu and $\mathrm{Law}^{17}$ devised an automatic mechanism reduction procedure, namely, the directed relation graph (DRG) method based on connectivity graph structures. The DRG method can be carried out with a linear scaling algorithm; thus, the computational cost for mechanism reduction scales linearly with the number of species ${ }^{18}$. Therefore, DRG is particularly suitable as the first step to reduce large mechanisms. Due to the simple concept and low computational cost, the DRG method has been widely used for skeletal mechanism reduction and many modifications and improvements have been made following the pioneering work of $\mathrm{Lu}$ and $\mathrm{Law}^{19-22}$.

In DRG method, the coupling between species is represented by a directed graph, in which each vertex denotes a species in the detailed mechanism, and an edge exists from vertex A to vertex B only if the removal of species B would directly induce significant error to the production rate of species A. The interaction coeffi- cient to measure the coupling effect between species and the graph search method is the key factor controlling the definitions and performances of different DRG based methods. After the pioneering work of $\mathrm{Lu}$ and Law, Pepiot-Desjardins and Pitsch ${ }^{19}$ introduced the concept of error propagation (EP) in DRG. In addition, the authors also proposed a different definition of the interaction coefficient to improve the performance of the method. Recently, in order to handle the large isomer groups in biodiesel mechanisms, a revised DRG approach with a different definition for the interaction coefficient is proposed by Luo et al. ${ }^{20}$. Further, in order to improve the prediction of reaction fluxes, the so-called path flux analysis (PFA) method was proposed in which both consumption and production pathways were used to measure the coupling effect between species for the skeletal reduction ${ }^{21}$.

Due to the differences among the above DRG based methods, when skeletal reduction is performed to the same detailed mechanisms, the different DRG based methods may obtain very different skeletal mechanisms ${ }^{23}$. Generally, the validation of the skeletal mechanism is usually through comparisons of simulation results of combustion properties with detailed mechanism. On the other hand, from the chemists' opinions, no matter what methods have been adopted for skeletal mechanism generation, the realistic chemical kinetics and the major reaction pathways should be maintained, which means that the resulting skeletal mechanisms should preserve all of the important species and reactions to avoid some spurious error cancellation during numerical simulations $\mathrm{s}^{24,25}$. Therefore, a more in-depth analysis of different DRG based skeletal reduction methods is critical.

Based on the above considerations, in this work, we present a detailed comparison of contemporary DRG based methods. More specifically, four different definitions of the interaction coefficients in conjunction with both standard DRG and EP graph search methods are employed to construct skeletal mechanisms for methyl butanoate (MB) combustion by the removal of potentially redundant species without significant loss of the accuracy of the detailed mechanism. The detailed combustion mechanism of MB chosen in this work is due to the recent large amounts of utilization of biodiesel, which motivates intense research efforts to achieve a comprehensive understanding of biodiesel combustion chemistry. The combustion chemistry of MB provides a prototype to understand realistic combustion of biodiesel fuel $\mathrm{s}^{26,27}$. Particular attentions have been focused on the chemical kinetics of the resulting skeletal mechanisms from different DRG based methods.

\section{Mechanism reduction and analysis methods}

\subsection{DRG based methods}

The identification and elimination of unimportant species from the detailed mechanisms is complicated due to the coupling of the species. The connectivity graph structures in DRG method provide an effective solution for this problem. Fig. 1 illustrates the general idea of DRG. In all the DRG based methods, the first step is to map the reaction system into a graph structure, in which each 


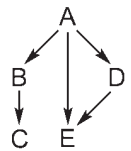

Fig.1 Scheme of the general idea of the DRG methods

vertex in the graph denotes a species as shown in Fig.1. If the removal of species $\mathrm{B}$ directly induces significant error to the production rate of species $\mathrm{A}$, then an edge exists from vertex A to vertex B. Thus, how to define the interaction coefficient to evaluate the direct influence of one species on another comes out to be the first question in DRG methods. In the original DRG method, the interaction coefficient was defined as ${ }^{17}$ :

$$
\begin{aligned}
& r_{\mathrm{AB}}^{\mathrm{Lu}}=\frac{\sum_{i=1, I}\left|v_{\mathrm{A}, i} \omega_{i} \delta_{\mathrm{B}}^{i}\right|}{\sum_{i=1, I}\left|v_{\mathrm{A}, i} \omega_{i}\right|} \\
& \delta_{\mathrm{B}}^{i}=\left\{\begin{array}{l}
1, \text { if the } i \text { th elementary reaction involves species B } \\
0, \text { otherwise }
\end{array}\right. \\
& \omega_{i}=\omega_{\mathrm{f}, i}-\omega_{\mathrm{b}, i}
\end{aligned}
$$

in which $r_{\mathrm{AB}}^{\mathrm{Lu}}$ is the relative error induced to species $\mathrm{A}$ by elimination of species $\mathrm{B}$, subscript $i$ indicates the $i$ th elementary reaction, $v_{\mathrm{A}, i}$ is the net stoichiometric coefficient of species $\mathrm{A}$ in the $i$ th reaction, and $\omega_{i}, \omega_{\mathrm{f}, i}$, and $\omega_{b, i}$ are the net, forward, and reverse reaction rates, respectively.

In order to handle the large isomer groups in biodiesel mechanism reductions, Luo et al. ${ }^{20}$ proposed a new definition for the interaction coefficient:

$$
r_{\mathrm{AB}}^{\mathrm{Luo}}=\frac{\max _{i}\left|v_{\mathrm{A}, i} \omega_{i} \delta_{\mathrm{B}}^{i}\right|}{\max _{i}\left|v_{\mathrm{A}, i} \omega_{i}\right|}
$$

Further, in order to improve the prediction of reaction fluxes, a more complicated interaction coefficient in the so-called path flux analysis (PFA) method was proposed ${ }^{21}$ :

$$
r_{\mathrm{AB}}^{\mathrm{PFA}}=r_{\mathrm{AB}}^{\text {1st-pro }}+r_{\mathrm{AB}}^{1 \text { st-des }}+r_{\mathrm{AB}}^{2 \text { st- pro }}+r_{\mathrm{AB}}^{2 \mathrm{st} \text {-des }}
$$

in which

$$
\begin{aligned}
r_{\mathrm{AB}}^{\text {1st-pro }} & =\frac{P_{\mathrm{AB}}}{\max \left(P_{\mathrm{A}}, D_{\mathrm{A}}\right)} \\
& =\frac{\sum_{i=1, I} \max \left(v_{\mathrm{A}, i} \omega_{i} \delta_{\mathrm{B}}^{i}, 0\right)}{\max \left(\sum_{i=1, I} \max \left(v_{\mathrm{A}, i} \omega_{i}, 0\right), \sum_{i=1, I} \max \left(-v_{\mathrm{A}, i} \omega_{i}, 0\right)\right)} \\
r_{\mathrm{AB}}^{\text {lst-des }} & =\frac{D_{\mathrm{AB}}}{\max \left(P_{\mathrm{A}}, D_{\mathrm{A}}\right)} \\
& =\frac{\sum_{i=1, I} \max \left(-v_{\mathrm{A}, i} \omega_{i} \delta_{\mathrm{B}}^{i}, 0\right)}{\max \left(\sum_{i=1, I} \max \left(v_{\mathrm{A}, i} \omega_{i}, 0\right), \sum_{i=1, I} \max \left(-v_{\mathrm{A}, i} \omega_{i}, 0\right)\right)} \\
r_{\mathrm{AB}}^{\text {2nd-pro }} & =\sum_{\mathrm{M}_{i} \neq \mathrm{A}, \mathrm{B}} r_{\mathrm{AM}}^{\text {stst pro }} r_{\mathrm{M}_{i} \mathrm{~B}}^{\text {lst-pro }} \\
r_{\mathrm{AB}}^{\text {2nd-des }} & =\sum_{\mathrm{M}_{i} \neq \mathrm{A}, \mathrm{B}} r_{\mathrm{AM}}^{\text {lst-des }} r_{\mathrm{M}_{i} \mathrm{~B}}^{1 \text { st-des }}
\end{aligned}
$$

In equations $(6)-(9), r_{\mathrm{AB}}^{\text {1st-pro }}$ and $r_{\mathrm{AB}}^{\text {1st-des }}$ denote the first generation for the production and destruction of species A via $\mathrm{B}$, while $r_{\mathrm{AB}}^{2 \mathrm{st} \text { pro }}$ and $r_{\mathrm{AB}}^{2 \mathrm{st}-\mathrm{des}}$ denote the second generation for the production and destruction of species between A and B via the third species $\left(\mathrm{M}_{i}\right)$. $P_{\mathrm{A}}$ and $D_{\mathrm{A}}$ represent the total production and destruction rates of species A, while $P_{\mathrm{AB}}$ and $D_{\mathrm{AB}}$ denote the production and destruction rates of species A due to the existence of species $\mathrm{B}$.
After the definition of the interaction coefficients, a depth first search is performed starting at user-selected target species (e.g., fuel, oxidizer) to find the dependency pathways for all species relative to the targets ${ }^{17}$. This procedure is iterated until no more important species are chosen and the reduced mechanism is thus generated by including only important species and reactions. The size of the reduced mechanism is controlled by a threshold value (c) which decides the existence of the vertex. However, in the standard procedures of DRG, it is assumed that every species selected to be kept in the mechanism is equally important, and neglects the connection length between the coupling species. For example, in Fig.1, if we select species A as the starting important species, species $\mathrm{C}$ is recognized as the same importance as species $\mathrm{B}$, which competently neglects the longer connection way to reach species A. In order to overcome this deficiency, Pepiot-Desjardins and Pitsch ${ }^{19}$ introduced the EP concept, in which the interaction coefficient is defined as the product of intermediate interaction coefficients along the connection ways. For example, the interaction coefficients of $r_{\mathrm{AC}}$ and $r_{\mathrm{AE}}$ in the EP procedure would be calculated as $r_{\mathrm{AC}}=r_{\mathrm{AB}} r_{\mathrm{BC}}$ and $r_{\mathrm{AE}}=\max \left(r_{\mathrm{AE}}^{\mathrm{dir}}, r_{\mathrm{AD}} r_{\mathrm{DE}}\right)$, in which $r_{\mathrm{AE}}^{\mathrm{dir}}$ denotes the direct interaction coefficient in Fig.1. PepiotDesjardins and Pitsch ${ }^{19}$ also defined a new interaction coefficient as following:

$$
\begin{aligned}
r_{\mathrm{AB}}^{\mathrm{DRGEP}} & =\frac{\left|P_{\mathrm{AB}}-D_{\mathrm{AB}}\right|}{\max \left(P_{\mathrm{A}}, D_{\mathrm{A}}\right)} \\
& =\frac{\left|\sum_{i=1, I} v_{\mathrm{A}, i} \omega_{i} \delta_{\mathrm{B}}^{i}\right|}{\max \left(\sum_{i=1, I} \max \left(v_{\mathrm{A}, i} \omega_{i}, 0\right), \sum_{i=1, I} \max \left(-v_{\mathrm{A}, i} \omega_{i}, 0\right)\right)}
\end{aligned}
$$

It is obvious that the four definitions of the interaction coefficients can be used in combination with both the standard DRG and the EP procedures, providing eight different DRG based skeletal reduction methods which are investigated in the present work.

\subsection{Element flux analysis}

In the present work, chemical kinetic analysis for MB combustion has been performed in order to check the species retained in the resulting skeletal mechanisms. The element flux analysis is used as the reaction path analysis method and is briefly outlined. In element flux analysis, the element flux for each element (such as C) from species $\mathrm{k}_{1}$ to $\mathrm{k}_{2}$ at instantaneous time $t$ is calculated via ${ }^{25}$ :

$$
E_{\mathrm{k}_{1} \rightarrow \mathrm{k}_{2}}(t)=\sum_{i=1}^{I} \frac{\omega_{i} N_{\mathrm{E}, \mathrm{k}_{1}} N_{\mathrm{E}, \mathrm{k}_{2}}}{N_{\mathrm{E}, i}}
$$

where $N_{\mathrm{E}, \mathrm{k}_{1}}, N_{\mathrm{E}, \mathrm{k}_{2}}$, and $N_{\mathrm{E}, i}$ are the number of atom $\mathrm{E}$ in species $\mathrm{k}_{1}$, species $\mathrm{k}_{2}$, and reaction $i$, respectively. To derive global reaction path information, a time- or space-integrated flux indicator should be used, e.g., the time-integrated flux during ignition simulations in the present work $^{25}$ :

$$
E_{\mathrm{int}, \mathrm{k}_{1} \rightarrow \mathrm{k}_{2}}=\int_{0}^{t} E_{\mathrm{k}_{1} \rightarrow \mathrm{k}_{2}}(t) \mathrm{d} t
$$

Consequently, the normalized weight of element flux from $k_{1}$ to $\mathrm{k}_{2}$ to the total out flux of species $\mathrm{k}_{1}$ can be easily derived as

$$
E_{\mathrm{rel}, \mathrm{k}_{1} \rightarrow \mathrm{k}_{2}}=\frac{E_{\mathrm{int}, \mathrm{k}_{1} \rightarrow \mathrm{k}_{2}}}{\sum_{\mathrm{k}}^{\mathrm{K}} E_{\mathrm{int}, k_{1} \rightarrow \mathrm{k}}}=\frac{\int_{0}^{\tau} E_{\mathrm{k}_{1} \rightarrow \mathrm{k}_{2}}(t) \mathrm{d} t}{\sum_{\mathrm{k}}^{\mathrm{K}} \int_{0}^{\tau} E_{\mathrm{k} 1 \rightarrow \mathrm{k}}(t) \mathrm{d} t}
$$


In the present work, both the above DRG based methods and the element flux analysis have been implemented as post-processing programs to deal with the results from Chemkin software ${ }^{28}$. The detailed mechanism for MB combustion is proposed by Dooley et al. ${ }^{29}$, which consists of 275 species and 1549 elementary reactions. To achieve a skeletal mechanism suitable over a wide range of applications, the DRG based methods are applied to reaction state points densely sampled from constant pressure autoignition simulations within the parameter range of pressure from $1.01 \times 10^{5}$ to $3.04 \times 10^{6} \mathrm{~Pa}$ and equivalence ratio from 0.5 to 2.0 . The initial temperature for constant pressure auto-ignition is set to be $650-1700 \mathrm{~K}$. It has been previously confirmed that reaction states solely sampled from auto-ignition simulations can exhibit good performance in generating skeletal mechanisms ${ }^{30}$.

\section{Results and discussion}

\subsection{Results of skeletal reduction}

As previously stated, the size of the skeletal mechanism is controlled by a threshold value which decides the existence of the vertex, and the resulting skeletal mechanisms can be traditionally validated via comparing simulation results of combustion properties with detailed mechanism. In order to check the performance of the skeletal mechanism for different combustion properties over a wide range of parameters, the validation procedures should cover the frequently-used combustion properties including ignition, extinction, and laminar flame speed. However, the generally used extinction simulations and laminar flame speed only represent high-temperature combustion properties, which cannot reflect the low-temperature combustion chemistry. Therefore, ignition delay time is selected as the only parameter for error control in mechanism reduction, and the error of the reduced mechanism is calculated via the following equation:

$$
\text { error }_{\text {rel }}=\frac{\left|\tau_{\text {ign,skel }}-\tau_{\text {ign,det }}\right|}{\tau_{\text {ign,det }}} \times 100 \%
$$

where $\tau_{\text {ign,skel }}$ and $\tau_{\text {ign,det }}$ represent ignition delay time due to the skeletal and detailed mechanisms, respectively. In this work, ignition delay time is defined as the time point when the temperature is increased by $400 \mathrm{~K}$ compared with the initial temperature.

Fig. 2 shows the number of species retained in the resulting skeletal mechanisms versus the threshold values by using the four definitions of the interaction coefficients in conjunction without or with the EP procedure, while Fig.3 exhibits the resulting skeletal mechanisms with different number of species versus the maximum error of the predicted ignition delay time at equivalence ratio $(\varphi)$ of 1.0 and pressure of $2.02 \times 10^{6} \mathrm{~Pa}$ within the temperature ranges from 700 to $1800 \mathrm{~K}$. For the four definitions of the interaction coefficients in combination with the standard DRG procedure, it can be seen that as the threshold value increases, the number of species retained in the resulting skeletal mechanisms by using the original DRG method ${ }^{17}$ decreases faster than the other three definitions. The results derived from the revised definition by Luo et $a .^{20}$ tend to be very stable as the threshold value increases. However, from Fig.3, it is obvious that the definition
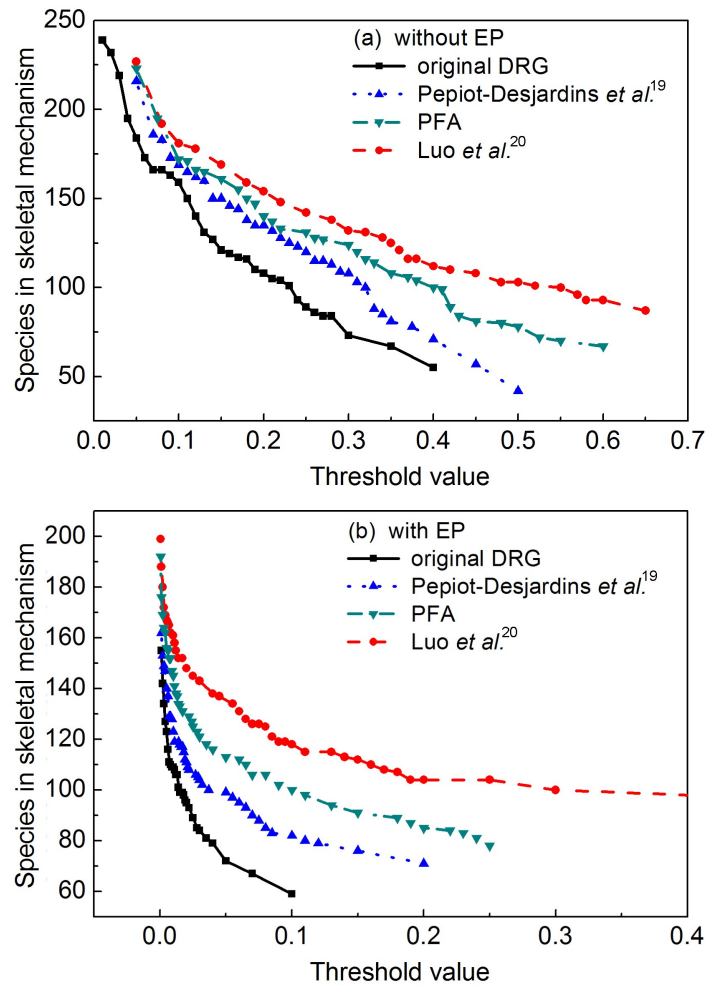

Fig.2 Species retained in the resulting skeletal mechanisms with respect to the threshold values by using different DRG based methods

proposed in the PFA method shows the best reduction results. The maximum relative error in the predicted ignition delay time is still within $10 \%$ even though the number of species retained in the skeletal mechanism has been reduced to be 104 . For the four definitions of the interaction coefficients in conjunction with the EP procedure, the number of the species in the derived skeletal mechanisms decreases much steeper as the threshold value increases. From the predicted error analysis of the ignition delay time as shown in Fig.3, it can be seen that the two definitions proposed in the PFA and original DRGEP methods ${ }^{19}$ exhibit better performance than the definitions in the original and Luo's revised DRG methods. The critical reason for the different performances in the resulting skeletal mechanisms is due to the species selections by the different definitions, and the combustion chemical kinetics in which degree can be captured by the skeletal mechanisms directly controls the performance of the skeletal mechanisms. Therefore, in the next section, a more in-depth analysis by combining systematic error analysis and chemical kinetic analysis has been performed to check the robustness of the resulting skeletal mechanisms via different DRG based methods.

\subsection{Robustness analysis of the skeletal mechanism}

In order to check the reliability of the resulting skeletal mechanisms, robustness analyses of the skeletal mechanisms have been performed through systematic error analysis of the predicted ignition delay time under a wide range of simulation conditions. Figs. 4 and 5 demonstrate the error analysis results of the predicted ignition delay times under certain simulation conditions by em- 

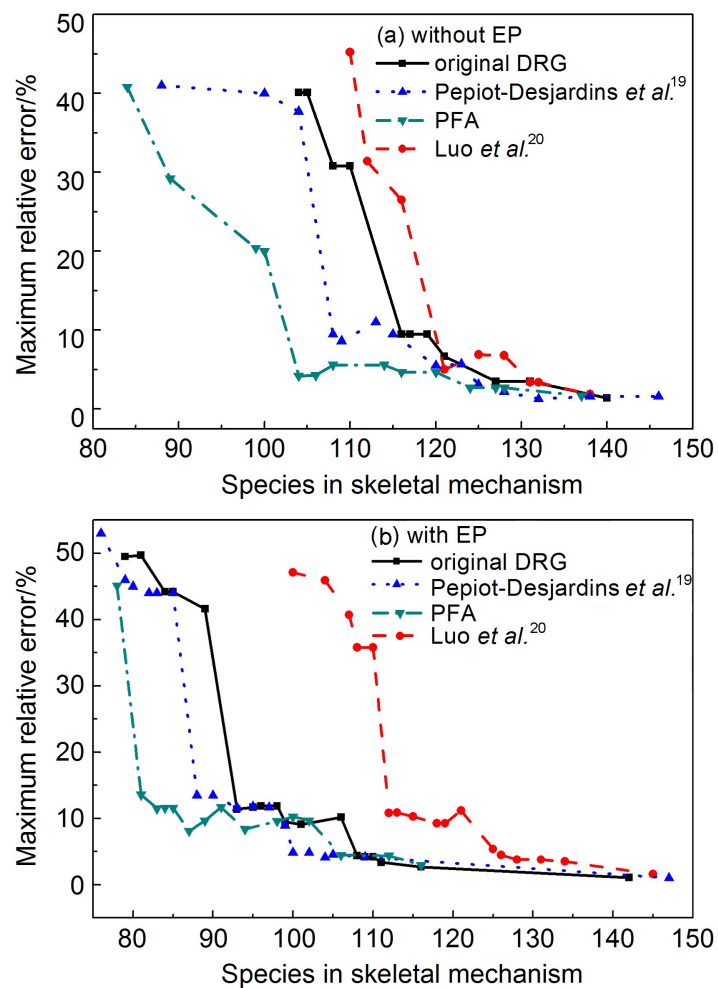

Fig.3 Skeletal mechanisms with different number of species versus the maximum error of the predicted ignition delay time

ploying the chosen resulting skeletal mechanisms derived from different reduction methods. The retained species in the corresponding skeletal mechanism together with the threshold value at which the skeletal mechanism is adopted are also explicitly shown in Figs. 4 and 5. It can be seen that the relative errors of the predicted ignition delay times under the selected simulation conditions via all the resulting skeletal mechanisms are within 15\%, indicating the good performances of the skeletal mechanisms. It is also noted that the maximum errors usually occur at fuel-lean combustion conditions. Further, it should be noted that when skeletal mechanisms with much less species are used, the relative errors of the predicted ignition delay times tend to increase more than $20 \%$ at some simulation conditions. Thus, the selected skeletal mechanisms used in Figs. 4 and 5 seem to be the best candidate skeletal mechanisms derived from corresponding reduction methods.

\subsection{Reaction path analysis}

Besides robustness analysis of the skeletal mechanism via different reduction methods based on systematic error analysis, reaction path analysis by employing the detailed mechanism has been performed to understand the realistic combustion chemistry processes. Time-integrated element flux analysis has been adopted to perform reaction path analysis in simulations of the constantvolume ignition processes. Fig. 6 shows the major initial reaction paths during the oxidation of MB at different temperatures. The percentages of the conversions (Figs.4-6) calculated from the detailed mechanism from top to bottom represent the analysis at initial temperatures of 700,900 , and $1200 \mathrm{~K}$ with equivalence ratio of 1.0 and pressure of $1.01 \times 10^{5} \mathrm{~Pa}$. The percentage of the conversions is defined as the percentage of the flux of element $\mathrm{C}$ from one species to another with respect to the total flux of $\mathrm{C}$.
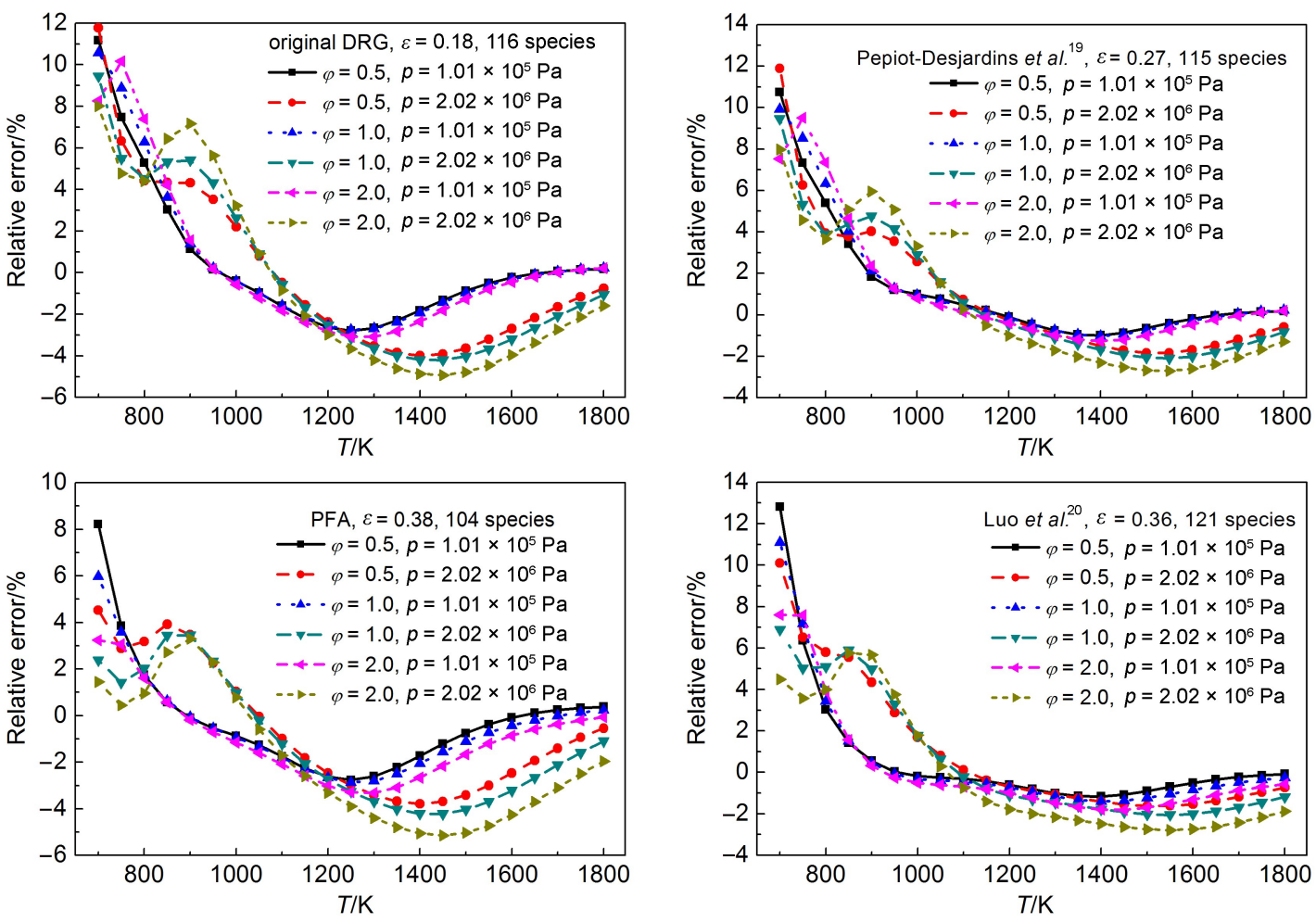

Fig.4 Relative errors of predicted ignition delay times using resulting skeletal mechanisms from the four DRG methods without EP procedure under certain simulation conditions 

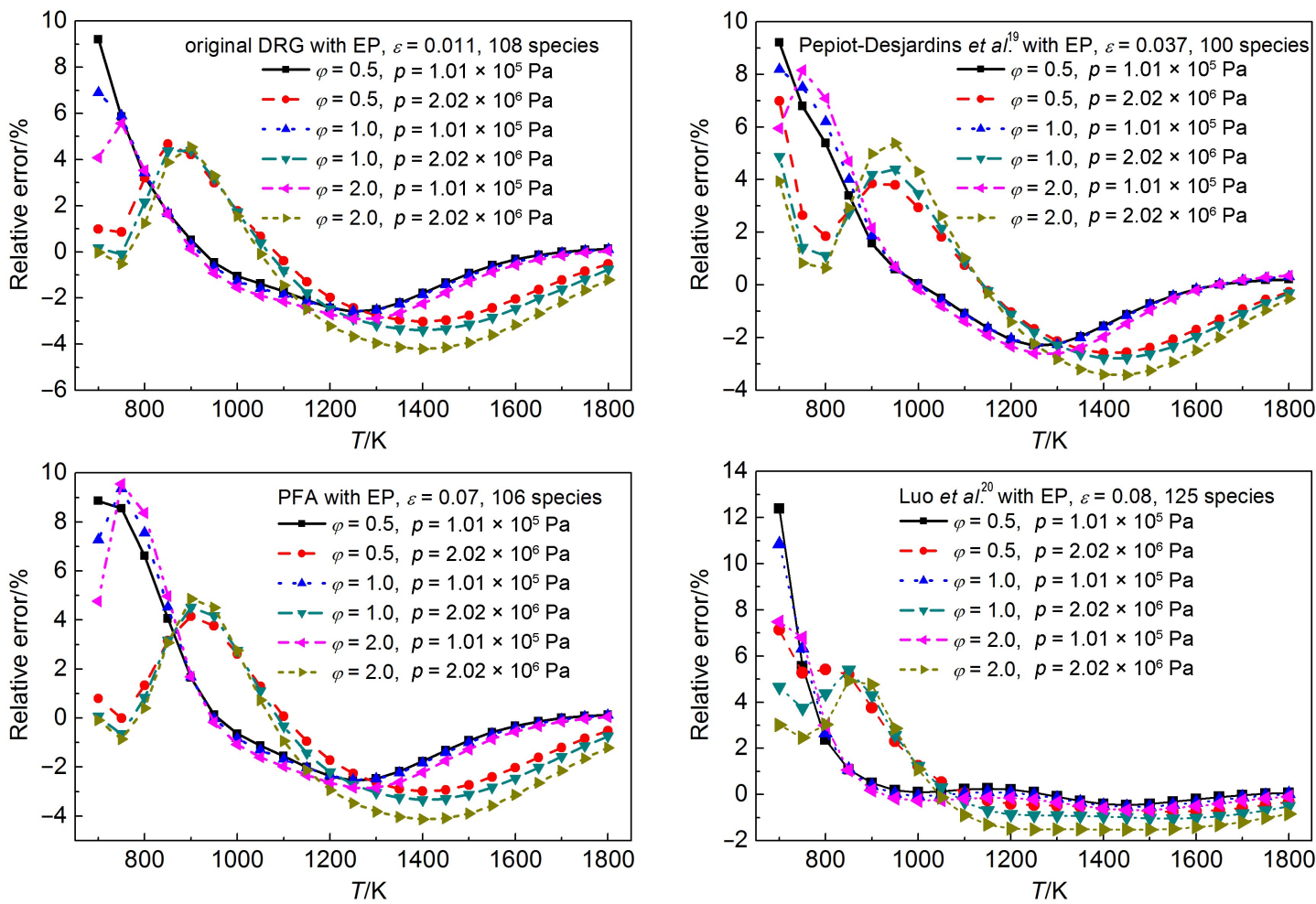

Fig.5 Relative errors of predicted ignition delay times using resulting skeletal mechanisms from the four DRG methods with EP procedures under certain simulation conditions

From Fig.6, it can be seen that the initial reaction path for $\mathrm{MB}$ is dominant by the $\mathrm{H}$-abstraction reactions to the formation of corresponding fuel alkyl radicals, namely, MBMJ, MB2J, MB3J and MB4J. The direct pyrolysis reactions of $\mathrm{MB}$ to the formation of BAOJ with $\mathrm{CH}_{3}$ (methyl radical) and ME2J with $\mathrm{C}_{2} \mathrm{H}_{5}$ (ethyl radical) only play a minor part. The following step is the $\beta$-scission reactions of the fuel alkyl radicals to the formation of small molecules, which proceed very fast. There are a number of reaction channels through which MB2J can decompose, but the pyrolysis reaction of MB2J to the production of MP2D with $\mathrm{CH}_{3}$ is dominant. For MBMJ, the following step is almost completely controlled by the $\beta$-scission reaction to the formation of formaldehyde $\left(\mathrm{CH}_{2} \mathrm{O}\right)$ and the $\mathrm{NC} 3 \mathrm{H} 7 \mathrm{CO}$ radical. MB3J and MB4J undergo similar reaction path to MBMJ, and the $\beta$-scission reaction controls the following step. It should be noted that at low temperatures, the primary fuel alkyl radicals also undergo the abstraction reaction of an $\mathrm{O}$ atom from $\mathrm{HO}_{2}$ or $\mathrm{RO}_{2}$ (e.g., $\mathrm{CH}_{3} \mathrm{O}_{2}$ ) to the formation of "MBXO", which represents the four alkoxy

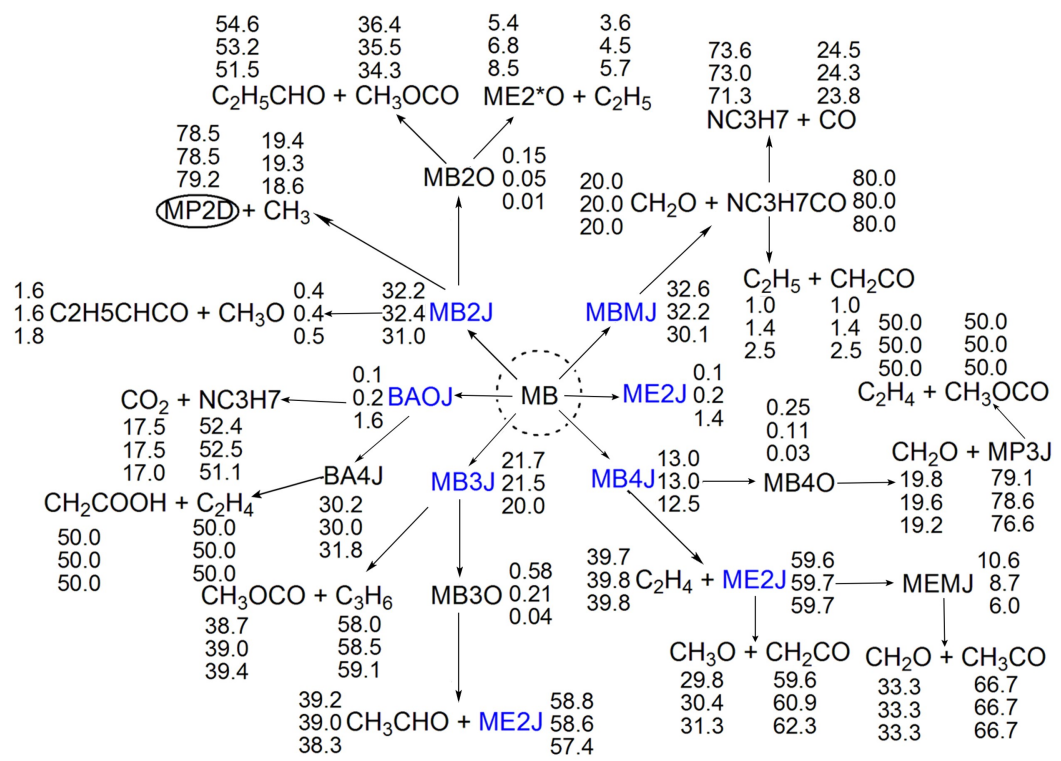

Fig.6 Time-integrated element flux analysis of MB during constant volume auto-ignition processes 


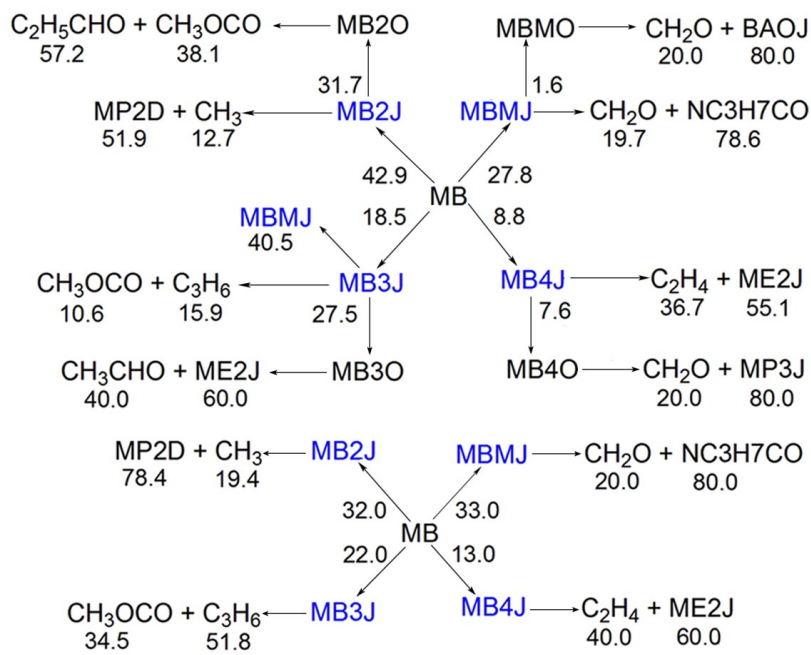

Fig.7 Initial reaction path for MB via instantaneous element flux analysis at $700 \mathrm{~K}$ (up) and $1200 \mathrm{~K}$ (down)

radicals. Fig.7 exhibits this phenomenon via instantaneous element flux analysis at 700 and $1200 \mathrm{~K}$ (the initial temperature of the simulation is $680 \mathrm{~K}$ with equivalence ratio of 1.0 and pressure of $1.01 \times 10^{5} \mathrm{~Pa}$.), which clearly demonstrates the different reaction paths of the four alkoxy radicals at low and high temperatures. The results of reaction path analysis are also in good agreement with the results via flux analysis by Dooley et $a l^{29}$. Figs.8 -9 show the reaction path analysis results for MP2D and $\mathrm{C}_{3} \mathrm{H}_{6}$ (propene), which are important intermediates during combustion processes of MB. For MP2D, there are a large number of reaction channels to undergo pyrolysis, and the $\mathrm{C}_{2}$ and $\mathrm{C}_{3}$ species constitutes the major products. The reaction paths for $\mathrm{C}_{3} \mathrm{H}_{6}$ and

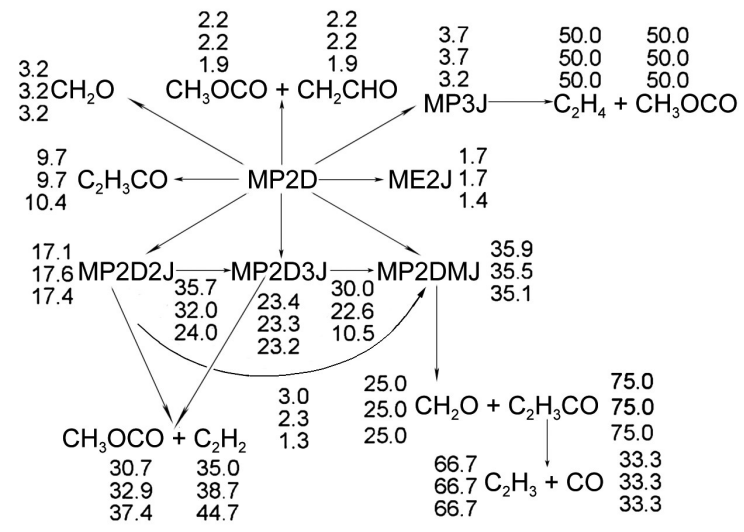

Fig.8 Time-integrated element flux analysis of MP2D during constant volume auto-ignition processes

other related small molecules including $\mathrm{C}_{2} \mathrm{H}_{4}$ (ethylene) and $\mathrm{C}_{2} \mathrm{H}_{2}$ (acetylene) are shown by Fig.9. The result is also in good agreement with previous studies ${ }^{25,29}$.

Given the reaction path analysis results via detailed mechanism, in order to check the chemical reality of the resulting skeletal mechanisms from different reduction methods, the retained species in different skeletal mechanisms with the predicted errors of ignition delay time controlled at the same level are compared in detail. Table 1 lists the species retained in the corresponding skeletal mechanisms derived from different reduction methods. There are 96 species retained in all the skeletal mechanisms, and the different species are explicitly given in Table 1. From Table 1 together with the previous reaction path analysis, it can be seen that the species needed to describe the major initial oxidation path of MB including the primary fuel alkyl radicals and the alkoxy

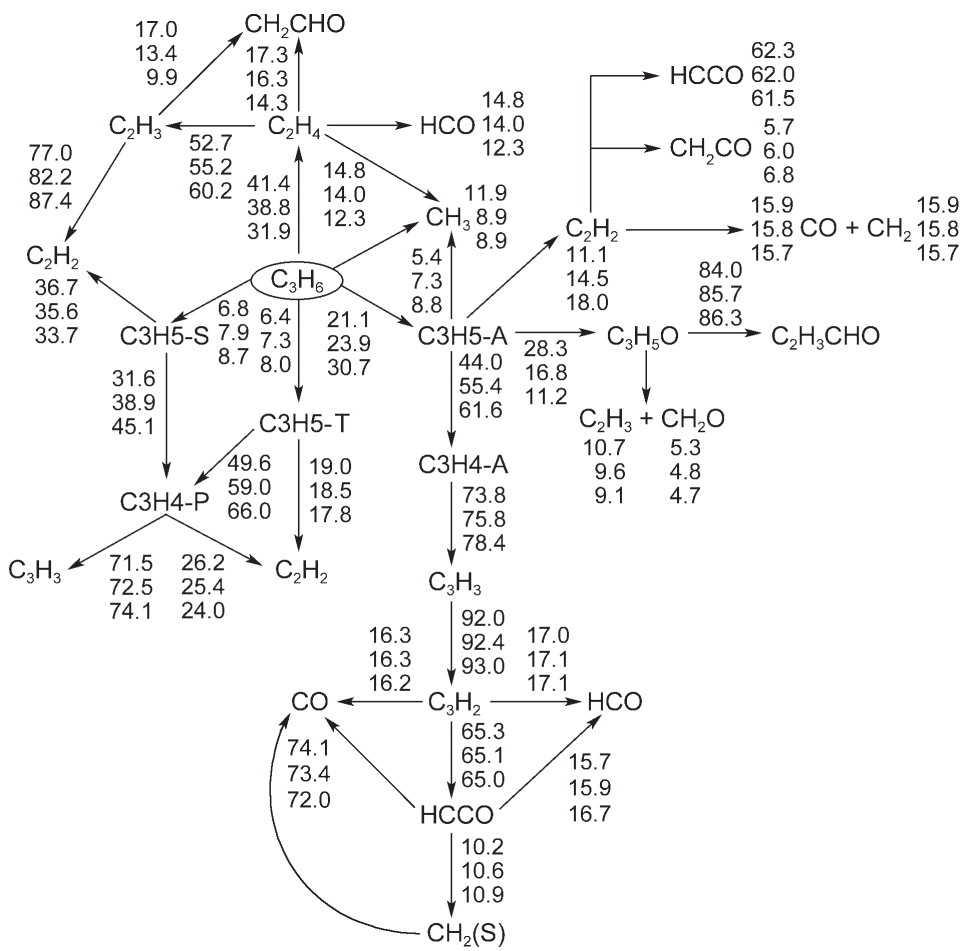

Fig.9 Time-integrated element flux analysis results of $\mathrm{C}_{3} \mathrm{H}_{6}$ during constant volume auto-ignition processes 
Table 1 Retained species in the corresponding skeletal mechanisms with the predicted errors of ignition delay time controlled within $15 \%$

\begin{tabular}{|c|c|c|c|c|}
\hline & Method & $\varepsilon$ & Species & Different species \\
\hline without & P original DRG & 0.18 & 116 & $\begin{array}{l}\text { IC3H5CHO, IC3H5CO, IC3H6CO, TC3H6OH, IC3H5OH, CH2CCH2OH, C3H5OH, } \\
\text { MB3D, CH3CHCOCH3, C2 } 33 \mathrm{COCH} 3, \text { IC4H7OH, NC3H7O, ME2*O, C3H6CHO-3, } \\
\text { IC4H8, IC4H7, SC2H4OH, CH3COCH3, CH3COCH2, TC3H6CHO }\end{array}$ \\
\hline & Pepiot-Desjardins et al..$^{19}$ & 0.27 & 115 & $\begin{array}{l}\text { IC3H5CHO, IC3H5CO, IC3H6CO, TC3H6OH, IC3H5OH, CH2CCH2OH, C3H5OH, } \\
\text { MB3D, NC3H7O, ME2*O, C3H6CHO-3, IC4H7, C4H8-1, SC2H4OH, CH3COCH3, } \\
\text { CH3COCH2, TC3H6CHO, IC4H7OH, NC3H7O2H }\end{array}$ \\
\hline & PFA & 0.38 & 104 & $\mathrm{IC} 3 \mathrm{H} 6 \mathrm{CO}, \mathrm{TC} 3 \mathrm{H} 6 \mathrm{OH}, \mathrm{C} 3 \mathrm{H} 6 \mathrm{O} 1-3, \mathrm{NC} 3 \mathrm{H} 7 \mathrm{O}, \mathrm{C} 2 \mathrm{H} 5 \mathrm{O}, \mathrm{C} 2 \mathrm{H} 5 \mathrm{O} 2 \mathrm{H}, \mathrm{CH} 3 \mathrm{COCH} 3, \mathrm{CH} 3 \mathrm{COCH} 2$ \\
\hline & Luo et al. ${ }^{20}$ & 0.36 & 121 & $\begin{array}{l}\text { IC3H5CHO, IC3H5CO, IC3H6CO, TC3H6OH, IC3H5OH, CH2CCH2OH, C3H5OH, } \\
\text { MB3D, CH3CHCOCH3, С2H3COCH3, C, IC3H7O2, NC3H7O, ME2*O, C3H6O1-3, } \\
\text { C2H5O, C4H8-1, SC2H4OH, C2H4O2H, C4H71-3, C2H4O1-2, CH3COCH3, CH3COCH2, } \\
\text { TC3H6CHO, C4H7O }\end{array}$ \\
\hline with EP & original DRG & 0.011 & 108 & $\begin{array}{l}\text { IC3H6CO, TC3H6OH, C, MB3D, IC3H7O2, NC3H7O, MBMO, C3H6O1-3, CH3CO3H, } \\
\text { CH3COCH3, } \mathrm{CH} 3 \mathrm{CO} 3, \mathrm{C} 2 \mathrm{H} 5 \mathrm{O}\end{array}$ \\
\hline & Pepiot-Desjardins et al..$^{19}$ & 0.037 & 100 & $\mathrm{MB} 3 \mathrm{D}, \mathrm{C}, \mathrm{MBMO}, \mathrm{SC} 2 \mathrm{H} 4 \mathrm{OH}$ \\
\hline & PFA & 0.07 & 106 & $\begin{array}{l}\text { IC3H6CO, MB3D, C, IC3H7O2, NC3H7O, MBMO, C3H6CHO-3, } \mathrm{CH} 3 \mathrm{CO} 3 \mathrm{H}, \mathrm{CH} 3 \mathrm{CO} 3 \text {, } \\
\text { C2 } 55 \mathrm{O}\end{array}$ \\
\hline & Luo et al. ${ }^{20}$ & 0.08 & 125 & $\begin{array}{l}\text { IC3H5CHO, IC3H5CO, IC3H6CO, TC3H6OH, IC3H5OH, CH2CCH2OH, C3H5OH, } \\
\mathrm{MB} 3 \mathrm{D}, \mathrm{CH} 3 \mathrm{CHCOCH} 3, \mathrm{C} 2 \mathrm{H} 3 \mathrm{COCH} 3, \mathrm{C}, \mathrm{IC} 3 \mathrm{H} 7 \mathrm{O} 2, \mathrm{NC} 3 \mathrm{H} 7 \mathrm{O}, \mathrm{MBMO}, \mathrm{ME} 2 * \mathrm{O}, \mathrm{C} 3 \mathrm{H} 6 \mathrm{O} 1- \\
\text { 2, } \mathrm{C} 3 \mathrm{H} 6 \mathrm{CHO}-3, \mathrm{C} 3 \mathrm{H} 6 \mathrm{O} 1-3, \mathrm{CH} 3 \mathrm{CO} 3 \mathrm{H}, \mathrm{C} 4 \mathrm{H} 71-3, \mathrm{C} 2 \mathrm{H} 5 \mathrm{O}, \mathrm{C} 4 \mathrm{H} 8-1, \mathrm{C} 4 \mathrm{H} 8-2, \mathrm{SC} 2 \mathrm{H} 4 \mathrm{OH}, \\
\mathrm{SC} 4 \mathrm{H} 9, \mathrm{C} 2 \mathrm{H} 5 \mathrm{O} 2 \mathrm{H}, \mathrm{CH} 3 \mathrm{COCH} 3, \mathrm{CH} 3 \mathrm{COCH} 2, \mathrm{TC} 3 \mathrm{H} 6 \mathrm{CHO}\end{array}$ \\
\hline species i & all skeletal mechanism & & 96 & 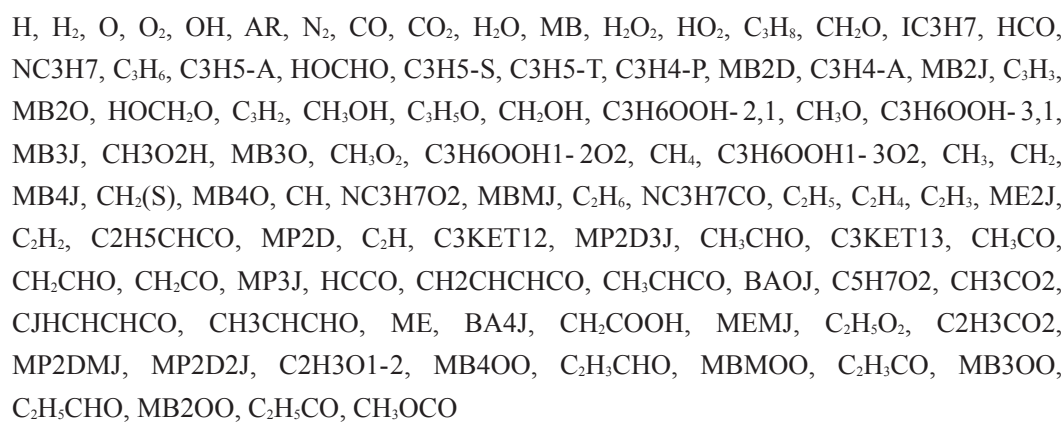 \\
\hline
\end{tabular}

radicals are well-reserved in all the skeletal mechanisms. The differences of the species among these skeletal mechanisms are mainly due to the $\mathrm{C}_{3}$ species. From the reaction path analysis, it is obvious that the species to describe the oxidation of $\mathrm{C}_{3} \mathrm{H}_{6}$ and other related small molecules are also covered by the 96 species existing in all skeletal mechanisms, which raises an interesting problem that whether the skeletal mechanism comprising of the 96 species can be a good candidate skeletal mechanism for MB combustion. Fig. 10 shows the relative errors of predicted ignition delay times by using the 96 species skeletal mechanism under various simulation conditions. Clearly, the ignition delay time can be well predicted by the 96 species skeletal mechanism and the maximum error is controlled within $10 \%$, indicating the good performance of the 96 species skeletal mechanism. In order to further check the robustness of the 96 species skeletal mechanism, laminar flame speed simulations are carried out by using the detailed and 96 species skeletal mechanism, respectively. Fig.11 shows the laminar flame speed as a function of the equivalence ratio at pressures of $1.01 \times 10^{5} \mathrm{~Pa}$ with initial inlet temperature of $400 \mathrm{~K}$. It can be seen that the skeletal mechanism also predicts the laminar flame speed accurately compared with the detailed mechanism, indicating that the 96 species skeletal mechanism also exhibits good performance in flame simulations. To further demonstrate the performance of the skeletal mechanism, species profiles in perfectly stirred reactor are also compared between detailed and reduced skeletal mechanism. Fig.12 shows the calculated mole fraction of some important species as a function of

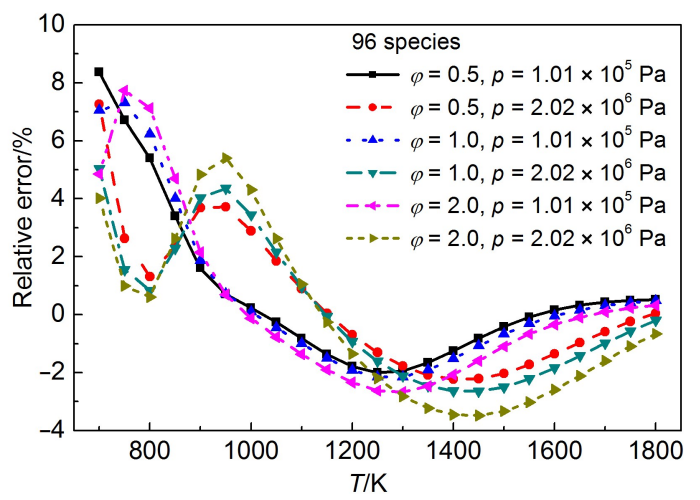

Fig.10 Relative errors of predicted ignition delay times using the 96 species skeletal mechanism under various simulation conditions 


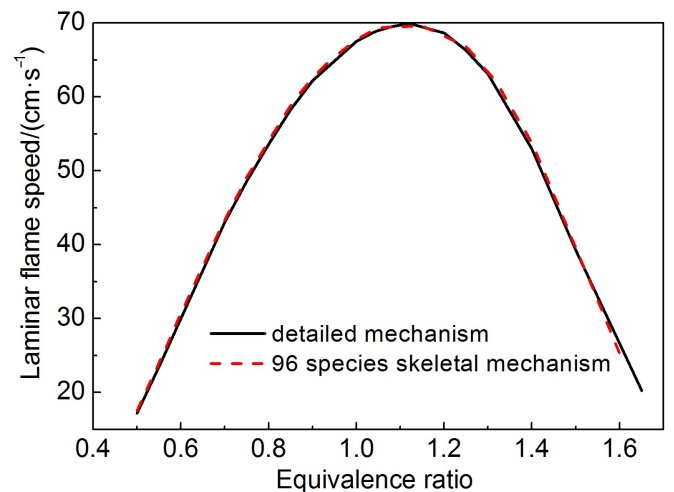

Fig.11 Laminar flame speed versus equivalence ratio predicted by the detailed and 96 species skeletal mechanism

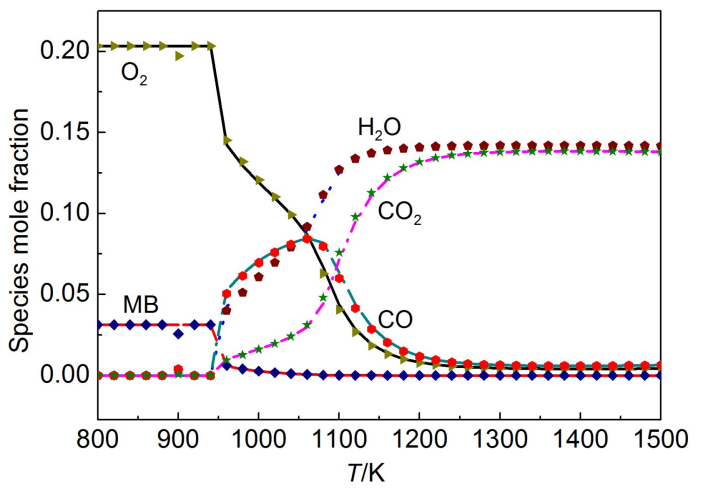

Fig.12 Mole fraction of major species as a function of temperature via detailed (lines) and 96 species skeletal mechanism (symbols)

temperature using the detailed and skeletal mechanisms, respectively, with equivalence ratio of 1.0 at a pressure of $1.01 \times 10^{5}$ $\mathrm{Pa}$, and residence time of $0.07 \mathrm{~s}$. It can be seen that the mole fractions of important species resulting from the skeletal mechanism are still rather close to those from the detailed mechanism, indicating the good performance of the 96 species skeletal mechanism. It should be noted that the current skeletal mechanism is not directly reduced for applications in practical computational fluid dynamics simulations, and it should be further reduced via the method of quasi-steady state approximation and so on in order to be used for engine designs.

\section{Conclusions}

In the present work, within the DRG framework, detailed comparisons of contemporary DRG based methods for skeletal reduction of detailed combustion mechanisms have been performed. Specifically, four contemporary different definitions of the interaction coefficients in conjunction with both standard DRG and EP graph search methods are considered and employed to construct skeletal mechanisms for MB combustion by removing potentially redundant species without significant loss of the accuracy of the detailed mechanism. Particular attentions have been focused on the retained species in the resulting skeletal mechanisms from different DRG based methods. Major findings and conclusions of this work are summarized as follows.
(1) Although the errors of predicted combustion properties by using skeletal mechanisms derived from different DRG based methods are controlled at the same level, the retained species in these skeletal mechanisms generated from different DRG based methods remains different due to the different selections of important species.

(2) A more in-depth analysis by combining systematic error analysis and chemical kinetic analysis has been performed to check the robustness of the resulting skeletal mechanisms via different DRG based methods. The PFA method and the original DRGEP method proposed by Pepiot-Desjardins and Pitsch exhibit better performance among the DRG based methods studied in this work.

(3) All of the skeletal mechanisms generated from different reduction methods demonstrate good performance in both predicting combustion properties and reserving chemical kinetics. However, none of the DRG based methods can directly create an optimal skeletal mechanism retaining all the important properties of the detailed mechanism but with the least species, implying that there is still a possibility to further improve the DRG approach.

(4) Reaction path analysis of reduced skeletal mechanisms is necessary beyond comparisons of simulation results with detailed mechanism. It is worth noting that only the results of reaction path analysis based on detailed mechanism are explicitly shown in this work because the important species demonstrated via reaction path analysis are all retained in the reduced skeletal mechanisms and they account for nearly one hundred percentage of the conversions of major species, which indicates that the results of reaction path analysis from skeletal mechanisms are nearly identical to the detailed mechanism.

(5) A 96 species skeletal mechanism for MB combustion is obtained via the idea of intersection of skeletal mechanisms from different reduction methods and further validated through simulations of key combustion properties. Reaction path analysis highlights the importance of propene chemistry during MB oxidation.

Acknowledgment: We thank National Supercomputing Center in Shenzhen for providing the computational resources and Chemkin software (v. 15131).

\section{References}

(1) Simmie, J. M. Prog. Energy Combust. Sci. 2003, 29, 599. doi: 10.1016/S0360-1285(03)00060-1

(2) Wang, Q. D. RSC Adv. 2014, 4, 4564. doi: 10.1039/c3ra45959d

(3) Guo, J. J.; Hua, X. X.; Wang, F.; Tan, N. X.; Li, X. Y. Acta Phys. -Chim. Sin. 2014, 30, 1027. [郭俊江, 华晓篖, 王 繁, 谈 宁馨, 李象远. 物理化学学报, 2014, 30, 1027.] doi: 10.3866/ PKU.WHXB201404031

(4) Westbrook, C. K.; Pitz, W. J.; Herbinet, O.; Curran, H. J.; Silke, E. J. Combust. Flame 2009, 156, 181. doi: 10.1016/j. combustflame.2008.07.014

(5) Battin-Leclerc, F.; Blurock, E.; Bounaceur, R.; Fournet, R.; 
Glaude, P. A.; Herbinet, O.; Sirjeana, B.; Wartha, V. Chem. Soc. Rev. 2011, 40, 4762. doi: 10.1039/C0CS00207K

(6) Battin-Leclerc, F. Prog. Energy Combust. Sci. 2008, 34, 440. doi: 10.1016/j.pecs.2007.10.002

(7) Xu, J. Q.; Guo, J. J.; Liu, A. K.; Wang, J. L.; Tan, N. X.; Li, X Y. Acta Phys. -Chim. Sin. 2015, 31, 643. [徐佳琪, 郭俊江, 刘 爱科, 王健礼, 谈宁馨, 李象远. 物理化学学报, 2015, 31, 643.] doi: 10.3866/PKU.WHXB201503022

(8) Lu, T. F.; Law, C. K. Prog. Energy Combust. Sci. 2009, 35, 192. doi: 10.1016/j.pecs.2008.10.002

(9) Fang, Y. M.; Wang, Q. D.; Wang, F.; Li, X. Y. Acta Phys. -Chim. Sin. 2012, 28, 2536. [方亚梅, 王全德, 王 繁, 李象远. 物理化学学报, 2012, 28, 2536.] doi: 10.3866/PKU. WHXB201208201

(10) Valorani, M.; Creta, F.; Goussis, D. A.; Lee, J. C.; Najm, H. N. Combust. Flame 2006, 146, 29. doi: 10.1016/j. combustflame.2006.03.011

(11) Valorani, M.; Creta, F.; Donato, F.; Najm, H. N.; Goussis, D. A. Proc. Combust. Inst. 2007, 31, 483. doi: 10.1016/j. proci.2006.07.027

(12) Prager, J.; Najm, H. N.; Valorani, M.; Goussis, D. A. Proc. Combust. Inst. 2009, 32, 509. doi:10.1016/j.proci.2008.06.074

(13) Løvås, T. Combust. Flame 2009, 156, 1348. doi:10.1016/j. combustflame.2009.03.009

(14) Nagy, T.; Turányi, T. Combust. Flame 2009, 156, 417. doi: 10.1016/j.combustflame.2008.11.001

(15) Zsély, I. G.; Nagy, T.; Simmie, J. M.; Curran, H. J. Combust. Flame 2011, 158, 1469. doi:10.1016/j. combustflame.2010.12.011

(16) Bendtsen, A. B.; Glarborg, P.; Dam-Johansen, K. Computers \& Chemistry 2001, 25, 161. doi:10.1016/S0097-8485(00)00077-2
(17) Lu, T. F.; Law, C. K. Proc. Combust. Inst. 2005, 30, 1333. doi: 10.1016/j.proci.2004.08.145

(18) Lu, T. F.; Law, C. K. Combust. Flame 2006, 144, 24. doi: 10.1016/j.combustflame.2005.02.015

(19) Pepiot-Desjardins, P.; Pitsch, H. Combust. Flame 2008, 154, 67. doi: 10.1016/j.combustflame.2007.10.020

(20) Luo, Z. Y.; Lu, T. F.; Maciaszek, M. J.; Som, S.; Longman, D. E. Energy Fuels 2010, 24, 6283. doi: 10.1021/ef1012227

(21) Sun, W.; Chen, Z.; Gou, X.; Ju, Y. Combust. Flame 2010, 157, 1298. doi: 10.1016/j.combustflame.2010.03.006

(22) Jiang, Y.; Qiu, R. Acta Phys. -Chim. Sin. 2009, 25, 1019. [蒋 勇, 邱 榕. 物理化学学报, 2009, 25, 1019.] doi: 10.3866/ PKU.WHXB20090426

(23) Tosatto, L.; Bennett, B. A. V.; Smooke, M. D. Combust. Flame 2013, 160, 1572. doi:10.1016/j.combustflame.2013.03.024

(24) Wang, Q. D. Energy Fuels 2013, 27, 4021. doi: 10.1021/ ef4007774

(25) Wang, Q. D.; Fang, Y. M.; Wang, F.; Li, X. Y. Proc. Combust. Inst. 2013, 34, 187. doi: 10.1016/j.proci.2012.06.011

(26) Fisher, E. M.; Pitz, W. J.; Curran, H. J.; Westbrook, C. K. Proc. Combust. Inst. 2000, 28, 1579. doi:10.1016/S0082-0784(00) 80555-X

(27) Coniglio, L.; Bennadji, H.; Glaude, P. A.; Herbinet, O.; Billaud, F. Prog. Energy Combust. Sci. 2013, 39, 340. doi: 10.1016/j.pecs.2013.03.002

(28) Chemkin, v. 15131; Reaction Design: San Diego.

(29) Dooley, S.; Curran, H. J.; Simmie, J. M. Combust. Flame 2008, 153, 2. doi: 10.1016/j.combustflame.2008.01.005

(30) Wang, Q. D.; Fang, Y. M.; Wang, F.; Li, X. Y. Combust. Flame 2012, 159, 91. doi: 10.1016/j.combustflame.2011.05.019 